\title{
Religiosity and decreased risk of substance use disorders: is the effect mediated by social support or mental health status?
}

\author{
Mark J. Edlund · Katherine M. Harris • \\ Harold G. Koenig · Xiaotong Han • \\ Greer Sullivan $\cdot$ Rhonda Mattox $\cdot$ Lingqi Tang
}

Received: 10 July 2008/ Accepted: 11 August 2009/Published online: 28 August 2009

(c) The Author(s) 2009. This article is published with open access at Springerlink.com

\begin{abstract}
Objective The negative association between religiosity (religious beliefs and church attendance) and the likelihood of substance use disorders is well established, but the mechanism(s) remain poorly understood. We investigated
\end{abstract}

M. J. Edlund $(\bowtie) \cdot X$. Han · G. Sullivan

Division of Health Services Research, Department of Psychiatry, College of Medicine, University of Arkansas for Medical

Sciences, 4301 W Markham, Slot 554, Little Rock,

AR 72205, USA

e-mail: mjedlund@uams.edu

K. M. Harris

RAND Corporation, 1200 S. Hayes Street, Arlington,

VA 22202, USA

H. G. Koenig

Duke University Medical Center, Box 3400, Durham,

NC 27710, USA

H. G. Koenig

Geriatric Research, Education and Clinical Center,

VA Medical Center, Durham, NC 27710, USA

G. Sullivan

VA South Central Mental Illness Research Education and Clinical Center, 2200 Ft Roots Drive, Bldg 58,

North Little Rock, AR 72114, USA

R. Mattox

Robert Wood Johnson Clinical Scholars Program,

University of California Los Angeles, 911 Broxton Plaza,

3rd Floor, Los Angeles, CA 90024, USA

L. Tang

Health Services Research Center,

Semel Institute for Neuroscience and Human Behavior,

10920 Wilshire Blvd., Suite 300, Los Angeles, CA 90024, USA whether this association was mediated by social support or mental health status.

Method We utilized cross-sectional data from the 2002 National Survey on Drug Use and Health $(n=36,370)$. We first used logistic regression to regress any alcohol use in the past year on sociodemographic and religiosity variables. Then, among individuals who drank in the past year, we regressed past year alcohol abuse/dependence on sociodemographic and religiosity variables. To investigate whether social support mediated the association between religiosity and alcohol use and alcohol abuse/dependence we repeated the above models, adding the social support variables. To the extent that these added predictors modified the magnitude of the effect of the religiosity variables, we interpreted social support as a possible mediator. We also formally tested for mediation using path analysis. We investigated the possible mediating role of mental health status analogously. Parallel sets of analyses were conducted for any drug use, and drug abuse/ dependence among those using any drugs as the dependent variables.

Results The addition of social support and mental health status variables to logistic regression models had little effect on the magnitude of the religiosity coefficients in any of the models. While some of the tests of mediation were significant in the path analyses, the results were not always in the expected direction, and the magnitude of the effects was small.

Conclusions The association between religiosity and decreased likelihood of a substance use disorder does not appear to be substantively mediated by either social support or mental health status.

Keywords Religious activity - Substance use disorders . Mental health $\cdot$ Social support $\cdot$ Mediators 


\section{Introduction}

Alcohol and drug disorders are common, occurring in $4-9 \%$ of the U.S. population in a given year $[16,26,27$, 57], and causing substantial morbidity [39], accounting for $12 \%$ of all disability in Western industrialized countries [40]. The negative social and health consequences associated with alcohol and drug disorders are well understood [49] and include lower employment outcomes [5, 37, 38], high rates of criminal justice involvement and violence $[4,10,12,15,36,51]$, and substantial medical/physical consequences [20, 48, 49].

The negative correlation between religiosity (religious beliefs and church attendance) and the likelihood of substance use disorders (of both alcohol and drugs) has been extensively documented in the U.S., [7, 29, 33, 36, 42, 44, 45, 53, 58] and Europe [19, 59, 61], but the mechanism(s) underlying this correlation remain poorly understood. Evidence does suggest that religiosity is most strongly associated with the decision to use or completely abstain from alcohol or drugs, and less strongly associated with abuse or dependence, among those who do drink or use drugs [36]. It is likely that prohibitions against the use of alcohol and drugs contained in some religious doctrines result in lower rates of substance abuse and dependence among individuals that subscribe to such beliefs.

However, there exists little research investigating other mechanisms that may also be involved. There are at least two potential mechanisms. First, it has been posited that the general salutary effects of religion might be due to increased social support [14, 47]. The increased social support afforded by religion might also influence the relationship between religious involvement and the likelihood of substance use disorders [43]. In particular social support might have two effects: (1) supporting social norms against alcohol use through stigma; and (2) providing a source of social interaction that does not involve alcohol or drugs. We call this the "social support mediation" hypothesis. This hypothesis has been tested in at least three samples; two samples of college students [11,35], and the other in a sample of young African-American adults [6]. These studies did not find evidence for the social support hypothesis.

A second potential mechanism is that better mental health among religious individuals may be a factor in their lower rates of substance use disorders. Individuals with mental health disorders have an increased likelihood of substance use disorders [16, 23, 27] and in those cases where mental health disorders are comorbid with substance use disorders, the mental health disorder typically precedes the substance use disorder [28], or is often independent of the substance use disorder [16]. Further, individuals who are more religious, or who attend church more frequently, have generally been found to have better mental health $[29,33]$.
Frequency of religious attendance is often a proxy for degree of religiousness; getting up on Sunday morning and spending that time at church instead of at the beach or fishing or having breakfast with friends, indicates that religion is important to the person. If important, then it is likely to be used when confronting psychological, social, and medical stressors. There is a wealth of research showing better coping and less depression among those who use religion to cope, both cross-sectional and longitudinal [31]. Furthermore, religious attendance has been shown to directly predict speed of remission from depression among stressed adults [30]. Religious attendance is also highly related with altruism, which is frequently related to lower rates of depression and other psychiatric disorders [50]. Thus, mental health may mediate the relationship between religiosity and the likelihood of having a substance use disorder. We call this the "mental health mediation" hypothesis.

In this paper we investigate these two potential underlying mechanisms using data from the National Survey on Drug Use and Health (NSDUH) $(n=36,370)$. The NSDUH survey is ideal for this purpose. It is nationally representative, includes DSM-IV measures of both alcohol abuse/dependence disorders and drug abuse/dependence disorders, and contains extensive information on possible confounders and mediators of the substance abuse and religion relationship, such as sociodemographic factors, mental health status, and social support. This is important, as one of the criticisms of prior work on religion and health in general is "the inability of studies to date to tease apart attendance from more general efforts to remain active in the community" [52].

Our first goal was to estimate, with the precision that our extremely large sample allows, the extent to which the lower likelihood of substance abuse or dependence disorder among the religious is due to abstinence from any substance use, and to what extent the lower likelihood is due to a lower likelihood of a substance use disorder, given some substance use. For example, religious people might have a lower likelihood of an alcohol use disorder because they are completely abstinent, or because among religious individuals who do drink, there are lower rates of alcohol use disorders. Second, we investigated whether the effects of church attendance and religious beliefs on the likelihood of substance use disorder were mediated by social support (social support mediation hypothesis). Third, we investigated whether the lower likelihood of substance use disorders among the religious is mediated by the fact that the religious generally have better mental health (mental health mediation hypothesis). To our knowledge, these questions regarding possible mediators have never been empirically investigated using nationally representative data. We conducted separate analyses for alcohol and drug use disorders. 


\section{Methods}

Sample

We utilized cross-sectional data from the 2002 NSDUH $(n=36,370)$. The Substance Abuse and Mental Health Services Administration conducts the NSDUH annually for the primary purpose of estimating the prevalence of illicit drug, alcohol, and tobacco use in the United States [54]. Our sample included respondents age 18 and older and has an average response rate of $75 \%$ [54]. The sample is described in Table 1.

After complete description of the study to the subjects, informed consent to continue the interview was obtained verbally. (Written consent was not obtained because the names of subjects are not used in the screening and interview process.) To assure confidentiality, questions about substance use, mental health problems, and treatment are completed though audio-assisted interview technology where respondents key their responses directly into a laptop computer. Remaining questions are completed through a computer assisted in-person interview. The survey is available at www.icpsr.umich.edu. Our analyses included all adult respondents.

Dependent variables

Past year use of alcohol and illicit drugs

National Survey on Drug Use and Health contains data that allowed us to construct binary indicators of any alcohol use in the past year, and any illicit drug use in the past year.

\section{Alcohol abuse/dependence and drug abuse/dependence}

National Survey on Drug Use and Health is a structured interview which contains items to construct DSM-IV diagnoses of past year alcohol abuse, alcohol dependence, drug abuse (for marijuana, hallucinogens, inhalants, tranquilizers, cocaine, heroin, pain relievers, stimulants, or sedatives), and drug dependence for the same drugs. We constructed binary indicators of whether the individual had an alcohol abuse/dependence disorder in the past year, or drug abuse/dependence disorder in the past year.

Independent variables

\section{Church attendance and religious beliefs}

The independent variables in the logistic regression models included three religiosity variables. The first variable was the number of times the subjects attended religious services (excluding weddings and funerals) in the past year.
Table 1 Descriptive statistics $(N=36,370)$

\begin{tabular}{|c|c|c|}
\hline Variable & $N$ & $\%$ Weighted \\
\hline \multicolumn{3}{|l|}{ Demographics } \\
\hline \multicolumn{3}{|l|}{ Age } \\
\hline 18-25 years old & 17,728 & 14.75 \\
\hline 26-34 years old & 5,530 & 16.71 \\
\hline $35-49$ years old & 8,306 & 31.09 \\
\hline 50 or older & 4,806 & 37.46 \\
\hline \multicolumn{3}{|l|}{ Gender } \\
\hline Male & 16,926 & 47.98 \\
\hline Female & 19,444 & 52.02 \\
\hline \multicolumn{3}{|l|}{ Race } \\
\hline Non-Hispanic White & 25,608 & 71.23 \\
\hline Non-Hispanic Black & 4,220 & 11.02 \\
\hline Hispanic & 4,344 & 11.95 \\
\hline Other & 2,198 & 5.79 \\
\hline \multicolumn{3}{|l|}{ Marital status } \\
\hline Married & 14,583 & 56.58 \\
\hline Widowed & 925 & 6.42 \\
\hline Divorced or separated & 3,292 & 13.48 \\
\hline Never been married & 17,570 & 23.52 \\
\hline \multicolumn{3}{|l|}{ Education } \\
\hline Less than high school & 6,363 & 17.70 \\
\hline High school & 12,249 & 32.30 \\
\hline Some college & 10,307 & 24.94 \\
\hline College graduate & 7,451 & 25.06 \\
\hline \multicolumn{3}{|l|}{ Income } \\
\hline Less than $\$ 20,000$ & 9,087 & 19.67 \\
\hline$\$ 20,000-\$ 49,999$ & 14,365 & 38.49 \\
\hline$\$ 50,000-\$ 74,999$ & 6,101 & 17.99 \\
\hline$\$ 75,000$ or more & 6,817 & 23.85 \\
\hline \multicolumn{3}{|l|}{ Other characteristics } \\
\hline \multicolumn{3}{|l|}{ Religiosity } \\
\hline \multicolumn{3}{|c|}{ Number of religious services in past year } \\
\hline 0 to 2 times & 17,902 & 45.98 \\
\hline 3 to 24 times & 9,188 & 23.94 \\
\hline 25 times or more & 9,112 & 30.08 \\
\hline \multicolumn{3}{|c|}{ My religious beliefs are very important } \\
\hline Agree/strongly agree & 26,882 & 78.12 \\
\hline Disagree/strongly disagree & 9,097 & 21.88 \\
\hline \multicolumn{3}{|c|}{ My religious beliefs influence my decisions } \\
\hline Agree/strongly agree & 24,861 & 74.52 \\
\hline Disagree/strongly disagree & 11,134 & 25.48 \\
\hline \multicolumn{3}{|l|}{ Social support } \\
\hline \multicolumn{3}{|c|}{ Number of friends who you share personal issues/concerns with } \\
\hline None & 5,110 & 17.55 \\
\hline One & 6,035 & 16.52 \\
\hline Two to three & 16,151 & 42.63 \\
\hline Four to five & 4,683 & 12.03 \\
\hline More than five & 4,274 & 11.27 \\
\hline
\end{tabular}


Table 1 continued

\begin{tabular}{|c|c|c|}
\hline Variable & $N$ & $\%$ Weighted \\
\hline \multicolumn{3}{|c|}{ Number of friends who you spent time with } \\
\hline None & 4,121 & 14.62 \\
\hline One & 4,735 & 13.04 \\
\hline Two to three & 13,169 & 37.37 \\
\hline Four to five & 5,427 & 14.16 \\
\hline More than five & 8,814 & 20.81 \\
\hline \multicolumn{3}{|c|}{ Number of friends who really care/like about you } \\
\hline None & 1,889 & 6.02 \\
\hline One & 3,165 & 8.23 \\
\hline Two to three & 10,272 & 27.79 \\
\hline Four to five & 5,480 & 15.02 \\
\hline More than five & 15,314 & 42.94 \\
\hline \multicolumn{3}{|c|}{ Score indicating level of serious mental illness } \\
\hline $0-1$ & 11,660 & 37.35 \\
\hline $2-5$ & 11,650 & 32.19 \\
\hline 6 or More & 13,060 & 30.45 \\
\hline \multicolumn{3}{|l|}{ Dependent variable } \\
\hline \multicolumn{3}{|c|}{ Past year alcohol use } \\
\hline Yes & 27,401 & 69.75 \\
\hline No & 8,969 & 30.25 \\
\hline \multicolumn{3}{|c|}{ Past year alcohol abuse/dependence } \\
\hline Yes & 4,666 & 7.92 \\
\hline No & 31,704 & 92.08 \\
\hline \multicolumn{3}{|c|}{ Past year illicit drug use } \\
\hline Yes & 8,696 & 14.20 \\
\hline No & 27,674 & 85.80 \\
\hline \multicolumn{3}{|c|}{ Past year illicit drug abuse/dependence } \\
\hline Yes & 1,847 & 2.76 \\
\hline No & 34,523 & 97.24 \\
\hline
\end{tabular}

In NSDUH, participants were asked how often they had attended religious services in the past year ( 0 times, 1 to 2 times, 3 to 5 times, 6 to 24 times, 25+ times). In SAMHSA publications this has often been collapsed into 0 to 24 times vs $25+$ times, $[17,55,56]$ while a report from the National Center on Addiction and Substance Abuse at Columbia University using NSDUH data compared individuals who never attended religious services with those who attended at least weekly [44]. In this paper, we utilized categories of 0 to 2 times, 3 to 24 times, and 25 times or more, which we have used in prior work with NSDUH $[17,18]$.

The other two items were Likert scale questions "For each statement, please indicate whether you strongly disagree, disagree, agree, or strongly agree...Y Your religious beliefs are an important part of your life...Your religious beliefs influence how you make decisions in life." The importance of the subject's religious beliefs in his or her life was dichotomized with agree and strongly agree combined as one category and disagree and strongly disagree as the other; subjects' responses on whether religious beliefs influenced their decisions were similarly dichotomized.

\section{Social support}

The social support variables included number of friends (not including family members) the respondent shares personal issues and concerns with (none, one, two or three, four or five, and more than five), number of friends subjects spent time with (none, one, two or three, four or five, and more than five) and number of friends who really like or care about the subjects (none, one, two or three, four or five, and more than five). These were coded with a series of indicator variables.

\section{Mental health status}

Our measure of mental health status was based on a measure of non-specific psychological distress known as the "K6." The K6 was developed and validated for use in the National Health Interview Survey and subsequently included in the NSDUH [24, 25]. The K6 includes six questions that measure on a 0 to 4 scale how frequently respondents experienced symptoms of psychological distress (nervousness, hopelessness, restlessness, depressed, feeling worthless, feeling that everything is an effort) during the month in the past year when they were feeling their worst emotionally. These values were summed to yield a score between 0 and 24 indicating the level of psychological distress. We categorized these values into three groups with roughly equal numbers of subjects in each group based on its rank ( 0 to 1,2 to 5 , and 6 or more).

\section{Sociodemographic factors}

Covariates included age (18-25, 26-34, 35-49, and 50 or older), gender, race (non-Hispanic White, non-Hispanic Black, Hispanic, and other), marital status (married, widowed, divorced, or separated and never been married), education (less than high school, high school, some college, and college graduates or higher), and income $(<\$ 20,000, \$ 20,000$ $\$ 49,999, \$ 50,000-\$ 74,999$, and $\$ 75,000$ or more).

\section{Analyses}

We first used logistic regression to regress any alcohol use in the past year on sociodemographic factors and the religion variables (Table 2). We conducted a separate logistic regression to assess the effect of each religion variable, due to the multicollinearity among the three. Then, among individuals who drank in the past year, we regressed the 
Table 2 Effect of church attendance and religiosity on past year alcohol use and alcohol abuse/dependence, controlling for sociodemographics

\begin{tabular}{llllll}
\hline & \multicolumn{2}{c}{ Any alcohol use } & & \multicolumn{2}{c}{ Any alcohol abuse/dependence } \\
\cline { 2 - 3 } OR & $95 \%$ CI & & OR & $95 \%$ CI \\
\hline Church attendance & & & & \\
25 times or more & 1.00 & - & 1.00 & - \\
3 to 24 times & 2.09 & $1.85,2.35$ & & 1.49 & $1.21,1.84$ \\
0 to 2 times & 2.29 & $2.05,2.55$ & 1.67 & $1.37,2.04$ \\
Importance of religion & & & \\
Important & 1.00 & - & 1.00 & - \\
Not important & 1.55 & $1.40,1.71$ & 1.19 & $1.03,1.36$ \\
Importance of religion in making decisions & \\
Important & 1.00 & - & 1.00 & - \\
\multicolumn{2}{l}{ Not important } & 1.65 & $1.50,1.82$ & 1.20 & $1.07,1.35$ \\
\hline
\end{tabular}

binary indicator of past year alcohol abuse/dependence on the sociodemographic factors and the religion variables. Again we used a separate regression for each religion variable.

To investigate whether the relationship between any alcohol use and the religion variables, or between alcohol abuse/dependence and the religion variables among those who drank, might be mediated by social support, we then repeated the above models, adding the social support variables (Table 3 ). To the extent that these added predictors modified the magnitude of the effect of the religious variables, we interpreted social support as a possible mediator [3].

In an analogous fashion we investigated mental health status as a mediator between any alcohol use and the religious variables, or between alcohol abuse/dependence

Table 3 Effect of church attendance and religiosity on past year alcohol use and alcohol abuse/dependence controlling for sociodemographics and social support

\begin{tabular}{llllll}
\hline & \multicolumn{2}{c}{ Any alcohol use } & & \multicolumn{2}{c}{ Any alcohol abuse/dependence } \\
& OR & $95 \%$ CI & & OR & $95 \%$ CI \\
\hline Church attendance & & & & \\
25 times or more & 1.00 & - & & 1.00 & - \\
3 to 24 times & 2.14 & $1.90,2.42$ & & 1.49 & $1.21,1.84$ \\
0 to 2 times & 2.51 & $2.24,2.82$ & 1.67 & $1.36,2.04$ \\
Importance of religion & & & \\
Important & 1.00 & - & 1.00 & - \\
Not important & 1.59 & $1.44,1.77$ & 1.17 & $1.01,1.34$ \\
Importance of religion in & making decisions & \\
Important & 1.00 & - & 1.00 & - \\
Note important & 1.70 & $1.54,1.88$ & 1.18 & $1.05,1.33$ \\
\hline
\end{tabular}

and the religious variables, among those who drank (Table 4).

A parallel set of analyses was conducted for use of any illicit drugs, and drug abuse/dependence among those with any drug use (Tables 5, 6, 7). All these regression models were run with survey design variables incorporated for stratification, clustering and weighting using Survey Logistic procedure in SAS version 9.2.

Test of mediation

As a sensitivity analysis, and to test formally for mediation, we also conducted our analyses using path analysis techniques, utilizing Mplus version 5.1. These models formally incorporate a direct pathway (e.g., the pathway directly from religious attendance to the alcohol or drug outcomes)

Table 4 Effect of church attendance and religiosity on past year alcohol use and alcohol abuse/dependence controlling for sociodemographics and mental health status

\begin{tabular}{llllll}
\hline & \multicolumn{2}{c}{ Any alcohol use } & & \multicolumn{2}{c}{ Any alcohol abuse/dependence } \\
& OR & $95 \%$ CI & & OR & $95 \%$ CI \\
\hline Church attendance & & & & \\
25 times or more & 1.00 & - & 1.00 & - \\
3 to 24 times & 2.07 & $1.83,2.33$ & & 1.47 & $1.19,1.81$ \\
0 to 2 times & 2.28 & $2.05,2.54$ & & 1.65 & $1.34,2.02$ \\
Importance of religion & & & \\
Important & 1.00 & - & 1.00 & - \\
Not important & 1.54 & $1.39,1.71$ & 1.19 & $1.04,1.36$ \\
Importance of religion in making decisions & \\
Important & 1.00 & - & 1.00 & - \\
Not important & 1.66 & $1.51,1.83$ & 1.22 & $1.09,1.37$ \\
\hline
\end{tabular}

Table 5 Effect of church attendance and religiosity on past year drug use and drug abuse/dependence, controlling for sociodemographics

\begin{tabular}{|c|c|c|c|c|}
\hline & \multicolumn{2}{|c|}{ Any drug use } & \multicolumn{2}{|c|}{ Any drug abuse/dependence } \\
\hline & OR & $95 \% \mathrm{CI}$ & OR & $95 \% \mathrm{CI}$ \\
\hline \multicolumn{5}{|l|}{ Church attendance } \\
\hline 25 times or more & 1.00 & - & 1.00 & - \\
\hline 3 to 24 times & 2.00 & $1.73,2.32$ & 1.02 & $0.74,1.40$ \\
\hline 0 to 2 times & 2.79 & $2.44,3.19$ & 0.93 & $0.68,1.28$ \\
\hline \multicolumn{5}{|c|}{ Importance of religion } \\
\hline Important & 1.00 & - & 1.00 & - \\
\hline Not important & 1.76 & $1.57,1.99$ & 0.92 & $0.76,1.11$ \\
\hline \multicolumn{5}{|c|}{ Importance of religion in making decisions } \\
\hline Important & 1.00 & - & 1.00 & - \\
\hline Not important & 1.67 & $1.52,1.84$ & 1.06 & $0.86,1.30$ \\
\hline
\end{tabular}


Table 6 Effect of church attendance and religiosity on past year drug use and drug abuse/dependence, controlling for sociodemographics and social support

\begin{tabular}{llllll}
\hline & \multicolumn{2}{c}{ Any drug use } & & \multicolumn{2}{c}{ Any drug abuse/dependence } \\
\cline { 2 - 3 } \cline { 5 - 5 } \cline { 5 - 5 } & OR & $95 \% \mathrm{CI}$ & & OR & $95 \% \mathrm{CI}$ \\
\hline Church attendance & & & & \\
25 times or more & 1.00 & - & 1.00 & - \\
3 to 24 times & 2.01 & $1.72,2.33$ & & 1.02 & $0.74,1.41$ \\
0 to 2 times & 2.83 & $2.47,3.25$ & & 0.90 & $0.65,1.25$ \\
Importance of religion & & & \\
Important & 1.00 & - & 1.00 & - \\
Not important & 1.76 & $1.57,1.98$ & 0.88 & $0.74,1.05$ \\
Importance of religion in making decisions & \\
\multicolumn{2}{l}{ Important } & 1.00 & - & 1.00 & - \\
\multicolumn{2}{l}{ Not important } & 1.67 & $1.52,1.84$ & 1.03 & $0.84,1.27$ \\
\hline
\end{tabular}

Table 7 Effect of church attendance and religiosity on past year drug use and drug abuse/dependence, controlling for sociodemographics and mental health

\begin{tabular}{|c|c|c|c|c|}
\hline & \multicolumn{2}{|c|}{ Any use } & \multicolumn{2}{|c|}{ Any drug abuse/dependence } \\
\hline & OR & $95 \% \mathrm{CI}$ & OR & $95 \% \mathrm{CI}$ \\
\hline \multicolumn{5}{|l|}{ Church attendance } \\
\hline 25 times or more & 1.00 & - & 1.00 & - \\
\hline 3 to 24 times & 1.95 & $1.69,2.26$ & 0.95 & $0.69,1.31$ \\
\hline 0 to 2 times & 2.74 & $2.40,3.13$ & 0.90 & $0.67,1.22$ \\
\hline \multicolumn{5}{|c|}{ Importance of religion } \\
\hline Important & 1.00 & - & 1.00 & - \\
\hline Not important & 1.76 & $1.56,1.98$ & 0.97 & $0.78,1.20$ \\
\hline \multicolumn{5}{|c|}{ Importance of religion in making decisions } \\
\hline Important & 1.00 & - & 1.00 & - \\
\hline Not important & 1.69 & $1.53,1.86$ & 1.11 & $0.89,1.38$ \\
\hline
\end{tabular}

and an indirect pathway (e.g., the pathway from religious attendance to social support to the alcohol or drug outcomes). Testing the significance of the indirect pathway represents a formal significance test of mediation effects. These path models were estimated using mean and variance adjusted weighted least-squares estimator and the probit link function [41].

To show effect sizes of religiosity on study dependent variables, we present odds ratios (ORs) and 95\% confidence intervals from the logistic regressions in the tables, while reporting significant $P$-values for the indirect pathways from the path analyses in the text. We believe ORs, which can be calculated from exponentiating logistic regression coefficients, are easier to interpret and give the reader the best sense of the magnitude of the effects of the independent variables. However, we believe path techniques are the best way to formally test for mediation.

\section{Results}

In NSDUH, $46 \%$ of respondents reported attending church 0 to 2 times in the past year, $24 \%$ reported attending 3 to 24 times per year, and $30 \%$ reported attending 25 or more times per year (Table 1). Seventy-eight percent reported that religious beliefs were an important part of their lives, and $75 \%$ reported that their religious beliefs influenced the decisions they made.

In models that controlled for sociodemographic factors, but not other covariates, the three measures of religiosity were significantly associated with a lower likelihood of any past-year use of alcohol, and any past-year use of illicit drugs (Tables 2, 5). For example, compared to those who attended 25 to 52 times per year, the ORs for any alcohol use for those with occasional church attendance (3 to 24 times per year) and infrequent church attendance ( 0 to 2 times per year) were 2.09 and 2.29, respectively. Similarly, for those who said religion was not important in their lives, the odds of any alcohol use was 1.55 the odds for those who reported religion was important in their lives. Measures of religious attendance and religious beliefs were also significantly associated with a lower likelihood of abuse/ dependence among those with any alcohol use (although the magnitude of the effect was smaller than for the abstinence step), but religious attendance and religiosity were not significantly associated with drug abuse/dependence among those who used any illicit drugs.

The addition of social support variables had only small effects on the magnitude of the church attendance and religious beliefs coefficients in any of the alcohol use, drug use, alcohol abuse/dependence, or drug abuse/dependence regressions (Tables 3, 6). However, in our path analyses the indirect pathways (religiosity affecting social support, social support affecting alcohol, or drug outcome) were statistically significant in the relationship between the three measures of religious attendance/religiosity and any alcohol use $(P<0.001)$. In these regressions, religiosity was associated with greater social support and social support was positively associated with any drinking. For this reason, in the corresponding logistic regressions the magnitude of the ORs actually increased (e.g., from 1.55 for religion not being very important vs 1.00 for religion being important (Table 2) to 1.59 for religion not being very important vs 1.00 for religion being very important (Table 3) with the addition of the social support variables, rather than decreased as expected. Consistent with the relatively small changes in the ORs we observed with the addition of social support variables to our logistic regression models, the magnitudes of the indirect pathway regression coefficients were generally only about $10 \%$ the magnitude of the direct pathway regression coefficients. 
The addition of mental health status had only small effects on the church attendance and religiosity coefficients in the alcohol use, drug use, alcohol abuse/dependence, or drug/abuse dependence regressions (Tables 4, 7). However, when we tested the significance of the indirect pathway (e.g., religiosity influencing mental health, mental health influencing alcohol, or drug outcome), we found evidence for mental health mediation in the regression of alcohol abuse/dependence on church attendance $(P<0.001)$, and the regressions of any drug use on church attendance $(P<0.001)$ and any drug use on religious beliefs). These effects were in the direction we hypothesized, with the ORs for the religion variables decreasing with the addition of the mental health variables. Again, the magnitude of the coefficients for the indirect pathway was small compared to the magnitude of the coefficients for the direct pathway.

\section{Discussion}

Using a large, nationally representative community sample, we found a highly significant, negative relationship between religiosity and the presence of a substance use disorder in the past year. Consistent with prior research [36], our results strongly suggest that the lower likelihood of substance use disorder is due mainly to effects on abstinence, although the decreased likelihood of a substance use disorder among those who drink or use illicit drugs is not an unimportant factor.

Importantly, our multivariate models allow us to estimate the independent effects of religion, and compare the magnitude of these religious effects to the effects of sociodemographic factors. For example, in our analyses a strong predictor of alcohol use was gender (for males, $\mathrm{OR}=2.50$, reference group females). For sake of space, sociodemographic variables were not included in our tables. The gender effect was similar to the magnitude of the OR for any alcohol use among those who attended church 0 to 2 times per year, compared to the reference group of 25 times or more. Thus, not only is the negative association between religiosity and the likelihood of a substance use disorder significant, the magnitude of the effect is large.

Further, we found that religiosity is quite common. This is consistent with other national surveys that show the prominent role of religion in American life [13, 46]. Thus, the fact that religiosity is quite common, combined with the fact that there is a strong negative relationship between religiosity and substance abuse suggests that religion may play an important role in decreasing substance abuse in the United States.

To our knowledge, our hypotheses had not been directly investigated previously using national data. We found little evidence for either our "social support mediation" hypothesis or the "mental health mediation" hypothesis. That is, in some cases the indirect pathways were statistically significant; however, the inclusion of the mediating variables to our models had only small effects on the magnitude of the religion coefficients. We would note that this situation, in which relatively modest effects are highly significant, is not uncommon when analyzing extremely large data sets. Further, while we expected the magnitude of the OR to decrease with the addition of the putative mediators, in some cases it increased. That is, in some cases, in fully specified models, the effects of religion were even larger than in the unadjusted models, although, again, the magnitude of the change was modest.

This study has several important limitations. The NSDUH has no information on religious affiliation (e.g., whether an individual is Catholic, or Baptist, or Jewish), and so we were not able to investigate how this factor influenced the likelihood of a substance use disorder. We would refer interested readers to an excellent study by Michalak on this topic [36], and note that the strength of the association between religiosity and substance use disorders likely differs for different religious groups. This is not surprising, given the different views different religions take on alcohol, from utilizing it in their sacraments (e.g., Catholics) to completely forbidding its use (e.g., Mormons).

The literature describes several dimensions of religiosity, such as intrinsic religiosity (intrinsic motivators for religiosity, such as importance of religious beliefs) and extrinsic religiosity (extrinsic motivators for religiosity, such as becoming established in a community), or organized religiosity (religious attendance and participation in organized social religious activities) and non-organized religiosity (prayer, meditation) [1, 22, 33]. Although our study measured beliefs and attendance, NSDUH does not assess non-organized religiosity behaviors/indicators as prayer, meditation, or reading religious texts that have been posited elsewhere to be influential [32].

Because our data are cross-sectional, we can say nothing directly regarding causality, although there are three possible causal relationships. First, religion may be a causal factor in decreasing the likelihood of having a substance use disorder in the past year. Second, the use of alcohol may be a causal factor in decreasing religiosity and church attendance. In particular, if an individual is abusing substances or is substance dependent, he or she may be less likely to attend church because of feeling guilty or simply not having the time to attend church because he or she is spending that time seeking substances or using them. This alternative explanation does not, however, fit as well for our measures of religiosity other than church attendance (i.e., importance of religious beliefs, influence of religious 
beliefs on decisions, etc.). Third, there might be a common causal factor, for example a personality trait or genetic factor, that both increases the likelihood of substance use and abuse and decreases the probability of church attendance [21], such as novelty seeking [9].

Social support and mental health are linked, in that good social support may be associated with better mental health. Nevertheless, we feel it makes sense to investigate these variables separately. We would note that it is not unusual for variables in social science investigation to be associated with each other: race is linked with income and education, education is linked with income, health is linked with age, and so on. In our opinion, there are significant differences between church attendance and social support, and even more differences between social support and importance of religious beliefs. Clearly, many individuals who state that their religious beliefs are important do not have good social support, and not all individuals with good social support are religious.

Our cross-sectional data do not allow us to capture the variability that may occur over time in both an individual's drinking and drug use, and also in his or her religiosity.

Our work suggests many areas for future research, using both qualitative and quantitative techniques. In particular, given that religiosity is associated with lower rates of substance use disorders, and the magnitude of the relationship is large, future studies are needed to investigate what the "active ingredient" in religion is. The use of large national data sets such as in the present analysis allows us to investigate associations and some possible mediators, using relatively crude measures. However, qualitative studies might be important in disentangling these complex relationships and phenomena, and provide new hypotheses for future quantitative studies.

We also need to better understand possible moderators of the relationship between religiosity and alcohol and drug outcomes. That is, are the effects equally strong for men and women, or single and married individuals?

A traditional reason for identification of risk or protective risk factors for disease is to decrease risk factors and promote protective factors. However, there is no consensus on the clinical and public policy implications of the inverse association between religiosity and substance use disorders, or other diseases $[2,8,29,34,43,52,60]$. Obviously one key concern regarding promotion of religion as a possible means of decreasing substance abuse is separation of church and state [2], especially since many substance use services are government funded. Thus, we also need greater discussion of the clinical and public policy implications, if any, of this type of work.

In conclusion, using data from a large, nationally representative survey, we have shown that religious involvement is significantly associated with a lower likelihood of alcohol use, alcohol abuse/dependence, and drug use, and the magnitude of the effects is large. These effects do not appear to be mediated by either social support or mental health status. Prospective studies are needed to help sort out causal questions in the religion-substance abuse relationship.

Acknowledgments This research was supported by VA HSR\&D Career Award RCD 03-036 to Dr Edlund.

Open Access This article is distributed under the terms of the Creative Commons Attribution Noncommercial License which permits any noncommercial use, distribution, and reproduction in any medium, provided the original author(s) and source are credited.

\section{References}

1. Allport GW, Ross JM (1967) Personal religious orientation and prejudice. J Pers Soc Psychol 5(4):432-443

2. Anti-Defamation League The case against 'charitable choice' why government funding for faith-based social services endangers religious freedom. http://www.adl.org/charitable_choice

3. Baron RM, Kenny DA (1986) The moderator-mediator variable distinction in social psychological research: conceptual, strategic, and statistical considerations. J Pers Soc Psychol 51:1173-1182

4. Barry KL, Fleming MF, Greenley JR, Kropp S, Widlak P (1996) Characteristics of persons with severe mental illness and substance abuse in rural areas. Psychiatr Serv 47:88-90

5. Booth BM, Feng W (2002) The impact of drinking and drinking consequences on short-term employment outcomes in at-risk drinkers in six southern states. J Behav Health Serv Res 29:157-166

6. Bowie JV, Ensminger ME, Robertson JA (2006) Alcohol-use problems in young black adults: effects of religiosity, social resources, and mental health. J Stud Alcohol 67:44-53

7. Brown TL, Parks GS, Zimmerman RS, Phillips CM (2001) The role of religion in predicting adolescent alcohol use and problem drinking. J Stud Alcohol 62:696-705

8. Center for Substance Abuse Treatment Medication-assisted treatment for Opioid Addiction in Opioid Treatment Programs. (2005) Treatment improvement protocol (TIP) series 43. Substance Abuse and Mental Health Services Administration, Rockville

9. Cloninger CR (1986) A unified biosocial theory of personality and its role in the development of anxiety states. Psychiatr Dev 4:167-226

10. Craddock SG, Rounds-Bryant JL, Flynn PM, Hubbard RL (1997) Characteristics and pretreatment behaviors of clients entering drug abuse treatment: 1969 to 1993. Am J Drug Alcohol Abuse 23:43-59

11. Dulin PL, Hill RD, Ellingson K (2006) Relationships among religious factors, social support and alcohol abuse in a Western U.S. college student sample. J Alcohol Drug Educ 50:5-14

12. Flynn PM, Kristiansen PL, Porto JV, Hubbard RL (1999) Costs and benefits of treatment for cocaine addiction in DATOS. Drug Alcohol Depend 57:167-174

13. General Social Survey (2002) Custom frequency on "How often do you attend religious services?" American Religion Data Archive, University Park

14. George LK, Ellison CG, Larson DB (2002) Explaining the relationships between religious involvement and health. Psychol Inq 13:190-200 
15. Gfroerer J, Brodsky M (1993) Frequent cocaine users and their use of treatment. Am J Public Health 83:1149-1154

16. Grant BF, Stinson FS, Dawson DA, Chou SP, Dufour MC, Compton W, Pickering RP, Kaplan K (2004) Prevalence and cooccurrence of substance use disorders and independent mood and anxiety disorders: results from the national epidemiologic survey on alcohol and related conditions. Arch Gen Psychiatry 61(8):807-816

17. Harris KM, Edlund MJ, Larson SL (2006) Religious involvement and the use of mental health care. Health Serv Res 41(2):395-410

18. Harris KM, Larson S, Edlund MJ (2005) Use of prescription psychiatric drugs and religious service attendance. Psychiatr Serv 56(4):396

19. Hope LC, Cook CC (2001) The role of Christian commitment in predicting drug use amongst church affiliated young people. Ment Health Relig Cult 4:109-117

20. Kaku DA, Lowenstein DH (1990) Emergence of recreational drug abuse as a major risk factor for stroke in young adults. Ann Intern Med 113:821-827

21. Kendler KS, Gardner CO, Prescott CA (1997) Religion, psychopathology, and substance use and abuse: a multimeasure, genetic-epidemiologic study. Am J Psychiatry 154(3):322-329

22. Kendler KS, Liu X, Gardner CO, McCullough ME, Larson D, Prescott CA (2003) Dimensions of religiosity and their relationship to lifetime psychiatric and substance use disorders. Am J Psychiatry 160(3):496-503

23. Kessler RC (2004) The epidemiology of dual diagnosis. Biol Psychiatry 56:730-737

24. Kessler RC, Andrews G, Colpe LJ, Hiripi E, Mroczek DK, Normand SL, Walters EE, Zaslavsky AM (2002) Short screening scales to monitor population prevalences and trends in non-specific psychological distress. Psychol Med 32(6):959-976

25. Kessler RC, Barker PR, Colpe LJ, Epstein JF, Gfroerer JC, Hiripi E, Howes MJ, Normand SL, Manderscheid RW, Walters EE, Zaslavsky AM (2003) Screening for serious mental illness in the general population. Arch Gen Psychiatry 60(2):184-189

26. Kessler RC, Berglund P, Demler O, Jin R, Merikangas KR, Walters EE (2005) Lifetime prevalence and age-of-onset distributions of DSM-IV disorders in the National Comorbidity Survey Replication. Arch Gen Psychiatry 62:593-602

27. Kessler RC, Chiu WT, Demler O, Walters EE (2005) Prevalence, severity, and comorbidity of 12-month DSM-IV disorders in the National Comorbidity Survey Replication. Arch Gen Psychiatry 62:617-627

28. Kessler RC, Nelson CB, McGonagle KA, Edlund MJ, Frank RG, Leaf PJ (1996) The epidemiology of co-occurring addictive and mental disorders: implications for prevention and service utilization. Am J Orthopsychiatry 66(1):17-31

29. Koenig HG (2005) Faith and mental health: religious resources for healing. Templeton Foundation Press, Philadelphia

30. Koenig HG (2007) Religion and remission of depression in medical inpatients with heart failure/pulmonary disease. J Nerv Ment Dis 195:389-395

31. Koenig HG, Cohen HJ, Blazer DG, Pieper C, Meador KG, Shelp F, Goli V, DiPasquale B (1992) Religious coping and depression among elderly, hospitalized medically ill men. Am J Psychiatry 149:1693-1700

32. Koenig HG, George LK, Meador KG, Blazer DG, Ford SM (1994) The relationship between religion and alcoholism in a sample of community-dwelling adults. Hosp Community Psychiatry 45:225-231

33. Koenig HG, McCullough ME, Larson DB (2001) Handbook of religion and health. Oxford University Press, New York

34. Lomax JW, Karff RS, McKenny GP (2002) Ethical considerations in the integration of religion and psychotherapy: three perspectives. Psychiatr Clin North Am 25(3):547-559
35. Menagi FS, Harrell ZA, June LN (2008) Religiousness and college student alcohol use: examining the role of social support. J Relig Health 47:217-226

36. Michalak L, Trocki K, Bond J (2007) Religion and alcohol in the U.S. National Alcohol Survey: how important is religion for abstention and drinking. Drug Alcohol Depend 87:268-280

37. Mullahy J, Sindelar J (1991) Gender differences in labor market effects of alcoholism. Am Econ Rev 81:161-165

38. Mullahy J, Sindelar J (1996) Employment, unemployment, and problem drinking. J Health Econ 15:409-434

39. Murray C, Lopez A (1996) The global burden of disease: a comprehensive assessment of mortality and disability from diseases, injuries, and risk factors in 1990 and projected to 2020. The Harvard School of Public Health on Behalf of the World Health Organization and the World Bank, Boston

40. Murray CJ, Lopez AD (1996) Evidence-based health policylessons from the Global Burden of Disease Study. Science 274:740-743

41. Muthen LK, Muthen BO (2005) Mplus: statistical analysis with latent variables: user's guide. Muthen \& Muthen, Los Angeles

42. Nasim A, Utsey SO, Corona R, Belgrade FZ (2006) Religiosity, refusal efficacy, and substance use among AfricanAmerican adolescents and young adults. J Ethn Subst Abuse 5(3):29-49

43. National Center on Addiction and Substance Abuse at Columbia University So help me God: Substance abuse, religion and spirituality. (2001) National Center on Addiction and Substance Abuse at Columbia University (CASA), New York

44. National Center on Addiction Substance Abuse at Columbia University CASA Report: Spirituality and Religion Reduce Risk of Substance Abuse. Press Release-2001. Available at: http://www.casacolumbia.org/absolutenm/templates/ PressReleases.asp ? articleid $=115 \&$ zoneid $=48$

45. Patock-peckham JA, Hutchinson GT, Cheong J, Nagoshi CT (1998) Effect of religion and religiosity on alcohol use in a college student sample. Drug Alcohol Depend 49:81-88

46. Pew Research Center for the People and the Press (2002) Religion and politics: the ambivalent majority. Pew Research Center for the People and the Press, Washington. http://people-press.org/ reports/pdf/32.pdf

47. Powell LH, Shahabi L, Thoresen CE (2003) Religion and spirituality. Linkages to physical health. Am Psychol 58:36-52

48. Rich JA, Singer DE (1991) Cocaine-related symptoms in patients presenting to an urban emergency department. Ann Emerg Med 20:616-621

49. Room R, Babor T, Rehm J (2005) Alcohol and public health. Lancet 365:519-530

50. Schwartz C, Meisenhelder JB, Ma Y, Reed G (2003) Altruistic social interest behaviors are associated with better mental health. Psychosom Med 65:778-785

51. Siegal HA, Fisher JH, Rapp RC, Wagner JH, Forney MA, Callejo V (1995) Presenting problems of substance abusers in treatment: implications for service delivery and attrition. Am J Drug Alcohol Abuse 21:17-26

52. Sloan RP. Field analysis of the literature on religion, spirituality, and health. http://www.templetonadvancedresearchprogram.com/ TARP-sloan.pdf

53. Stone RA, Whitbeck LB, Chen X, Johnson K, Olson DM (2006) Traditional practices, traditional spirituality, and alcohol cessation among American Indians. J Stud Alcohol 67(2):236-244

54. Substance Abuse and Mental Health Services Administration (2002) Summary of findings from the 2001 National Household Survey on Drug Abuse volume II technical appendices and selected tables. Office of Applied Studies, Rockville

55. Substance Abuse and Mental Health Services Administration Office of Applied Studies (2007) The NSDUH report: religious 
involvement and substance use among adults. Office of Applied Studies, Rockville

56. Substance Abuse Mental Health Services Administration (2003) Results from the 2002 National Survey on Drug Use and Health: National Findings. Office of Applied Studies, NSDUH Series H22, Rockville

57. Substance Abuse Mental Health Services Administration: Office of Applied Studies (2000) Summary of findings from the 2000 National Household Survey on Drug Abuse. Department of Health and Human Services, Rockville

58. Sussman S, Skara S, Rodriguez Y, Pokhrel P (2006) Non drug use- and drug use-specific spirituality as one-year predictors of drug use among high-risk youth. Subst Use Misuse 41(13):18011816

59. Szaflarski M (2001) Gender, self-reported health, and healthrelated lifestyles in Poland. Health Care Women Int 22:207-227

60. Wang PS, Berglund PA, Kessler RC (2003) Patterns and correlates of contacting clergy for mental disorders in the United States. Health Serv Res 38:647-673

61. Winter T, Karvonen S, Rose RJ (2002) Does religiousness explain regional differences in alcohol use in Finland? Alcohol Alcohol 37:330-339 